\title{
Transmission of Leishmania infantum from cats to dogs
}

\author{
Transmissão de Leishmania infantum de gatos para cães
}

\author{
Joilson Ferreira Batista1; Francisco das Chagas Ribeiro Magalhães Neto'; \\ Kayo Sandro Pimentel do Prado Lopes ${ }^{1}$; Marcello Otake Sato²; Carlos Henrique Nery Costa; \\ Ivete Lopes de Mendonça** (i)
${ }^{1}$ Laboratório de Sanidade Animal, Universidade Federal do Piauí - UFPI, Teresina, PI, Brasil ${ }^{2}$ Department of Tropical Medicine and Parasitology, Dokkyo Medical University, Kitakobayashi, Mibu, Japan ${ }^{3}$ Departamento de Medicina Comunitária, Universidade Federal do Piauí - UFPI, Teresina, PI, Brasil ${ }^{4}$ Departamento de Clínica e Cirurgia Veterinária, Universidade Federal do Piauí - UFPI, Teresina, PI, Brasil

How to cite: Batista JF, Magalhães Neto FCR, Lopes KSPP, Sato MO, Costa CHN, Mendonça IL. Transmission of Leishmania infantum from cats to dogs. Braz J Vet Parasitol 2020; 29(4): e017820. https://doi.org/10.1590/S1984-29612020099

\begin{abstract}
Leishmania infantum infection in cats has been reported in several countries, including Brazil. However, the transmission of visceral leishmaniasis (VL) from cats to another host has not been proven yet. Therefore, the aim of this study was to verify the possibility of $L$. infantum transmission from cats to dogs. In order to verify the possibility of VL transmission from the cat to the dog, xenodiagnosis was carried out in a VL-positive cat, using 55 female Lutzomyia longipalpis. Five days later, 40 insects were dissected to verify Leishmania infection. The remaining 15 females were fed in a healthy dog. The potential infection of the dog was verified through clinical, serological, parasitological examinations, and PCR, at three, six, and twelve months post-infection. All 55 L. Iongipalpis females became visibly engorged. Leishmania promastigotes were detected in $27.5 \%$ of the dissected insects. Leishmania infection in the dog was confirmed upon first evaluation. DNA sequencing of the parasite isolated from the cat confirmed $L$. infantum infection and showed $99 \%$ similarity with the $L$. infantum DNA sequences from the dogs. Through this study, it was possible to confirm the $L$. infantum experimental transmission from a domestic cat to a domestic dog through its biological vector L. longipalpis.
\end{abstract}

Keywords: Xenodiagnoses, transmission, leishmaniasis, feline, dog.

\begin{abstract}
Resumo
A infecção por Leishmania infantum em gatos tem sido relatada em vários países, incluindo o Brasil. No entanto, a transmissão da leishmaniose visceral (LV) de gatos para outro hospedeiro ainda não foi comprovada. Portanto, o objetivo deste estudo foi verificar a possibilidade de transmissão de L. infantum de gatos para cães. Para verificar a possibilidade de transmissão da LV do gato para o cão, foi realizado xenodiagnóstico em um gato com LV, utilizando-se 55 fêmeas de Lutzomyia longipalpis. Cinco dias depois, 40 insetos foram dissecados para verificar a infecção por Leishmania. As 15 fêmeas restantes foram alimentadas em um cão saudável. A possível infecção no cão foi verificada por meio de exames clínicos, sorológicos, parasitológicos e PCR, três, seis e doze meses após a infecção. Todas as 55 fêmeas de L. longipalpis ficaram visivelmente ingurgitadas. Promastigotas de Leishmania foram detectadas em $27,5 \%$ dos insetos dissecados. A infecção por Leishmania no cão foi confirmada na primeira avaliação. O sequenciamento do DNA do parasito isolado do gato confirmou a infecção por $L$. infantum e apresentou $99 \%$ de similaridade com sequências de DNA de L. infantum de cães. Através deste estudo, foi possível confirmar a transmissão experimental de $L$. infantum de um gato doméstico para um cão doméstico através do seu vetor biológico L. longipalpis.
\end{abstract}

Palavras-chave: Xenodiagnóstico, transmissão, leishmaniose, felino, cachorro. 


\section{Introduction}

Visceral leishmaniasis (VL) is an infection caused by a protozoan of the genus Leishmania, which affects both humans and several domestic and wild animal species (Harhay et al., 2011; Zanette et al., 2014), including domestic cats (Felis catus). It is a systemic disease caused by Leishmania species, which are part of the Donovani complex. Leishmania infantum (syn. Leishmania chagasi) is responsible for causing VL in the New World, part of Africa and Europe and has dogs as its main reservoir (Harhay et al., 2011; Marcondes \& Rossi, 2013).

VL presents wide distribution in Brazil and it is reported in all regions of the country (Souza et al., 2009). In Teresina, capital of Piauí, Brazil, this disease is endemic, and has even affected the cats. It is registered that three domestic cats were infected with L. infantum out of 83 animals examined (Mendonça et al., 2017a).

The first case of natural infection in feline caused by Leishmania sp. in Brazil was registered in 1939, in a cat with ulcers in its nose and ear, in the state of Pará. However, the causative specie was not identified (Mello, 1940). Other studies carried out in Brazil reported L. infantum infections in domestic cats in the cities of Cotia, Araçatuba, Andradina, and Pirassununga, state of São Paulo, Campo Grande, state of Mato Grosso do Sul, and Teresina (Savani et al., 2004; Vides et al., 2011; Coelho et al., 2011; Benassi et al., 2017; Metzdorf et al., 2017; Mendonça et al., 2017a).

The possible transmission of $L$. infantum from cats to dogs adds relevant information on the epidemiology of leishmaniasis in Brazil. Reports of the disease in domestic cats in the country (Savani et al., 2004; Vides et al., 2011; Coelho et al., 2011; Benassi et al., 2017; Metzdorf et al., 2017; Mendonça et al., 2017a; Asfaram et al., 2019), the demonstration that cats infected with L. infantum have a high capacity to infect Lutzomyia. longipalpis (Mendonça et al., 2020) and the possible transmission of infection from these animals to dogs is of great concern, since, domestic cats have a very close contact with dogs and humans and can be highly important in the spread of leishmaniasis in the urban environment.

Previous studies on the role of felines in the VL biological cycle reported potential infections of Phlebotomus perniciosus and L. longipalpis by L. infantum while performing xenodiagnosis on infected feline (Maroli at al., 2007; Silva et al., 2010; Mendonça et al., 2020). However, no previous study has evaluated the possibility of VL transmission from felines to another susceptible host. Therefore, this study was carried out to verify the possibility of VL transmission from a cat infected by L. infantum to an uninfected dog through L. longipalpis, a laboratory insect.

\section{Methodology}

\section{Place of study}

The study was carried out at the Animal Health Laboratory (LASAN) of the Federal University of Piauí (UFPI), Teresina, state of Piauí, Brazil in partnership with the Natan Portella Institute of Tropical Diseases (Leishmaniasis Laboratory) in Teresina and the Department of Tropical Medicine and Parasitology, Dokkyo Medical University, Tochigi, Japan.

\section{Ethics statements}

The study meets the norms issued by the National Council of Animal Experimentation Control (CONCEA), and was approved by the Ethics Committee on Animal Use (CEUA) of the Federal University of Piauí (UFPI), under accession number 102/2015.

\section{Experimental design}

Two animals were enrolled in this study; a domestic cat (Felis catus) naturally infected by L. infantum and an uninfected domestic dog (Canis familiaris).

In order to verify possibility of VL transmission from the feline to the dog, xenodiagnosis was performed on the VL-bearing cat. On the fifth and sixth day post-xenodiagnosis, the same insects were placed to feed on the healthy dog. The possible infection and disease progress in the dog were verified through clinical, serological, and parasitological examinations for VL (Figure 1).

\section{Feline characteristics}

An eight years old VL-carrier Siamese feline was donated by its owner to participate in the study. The clinical examination revealed generalized lymphadenomegaly, skin lesion, nodules of softened consistency at the edges of the ears, alopecia in the ears, and uveitis (Figure 2). 


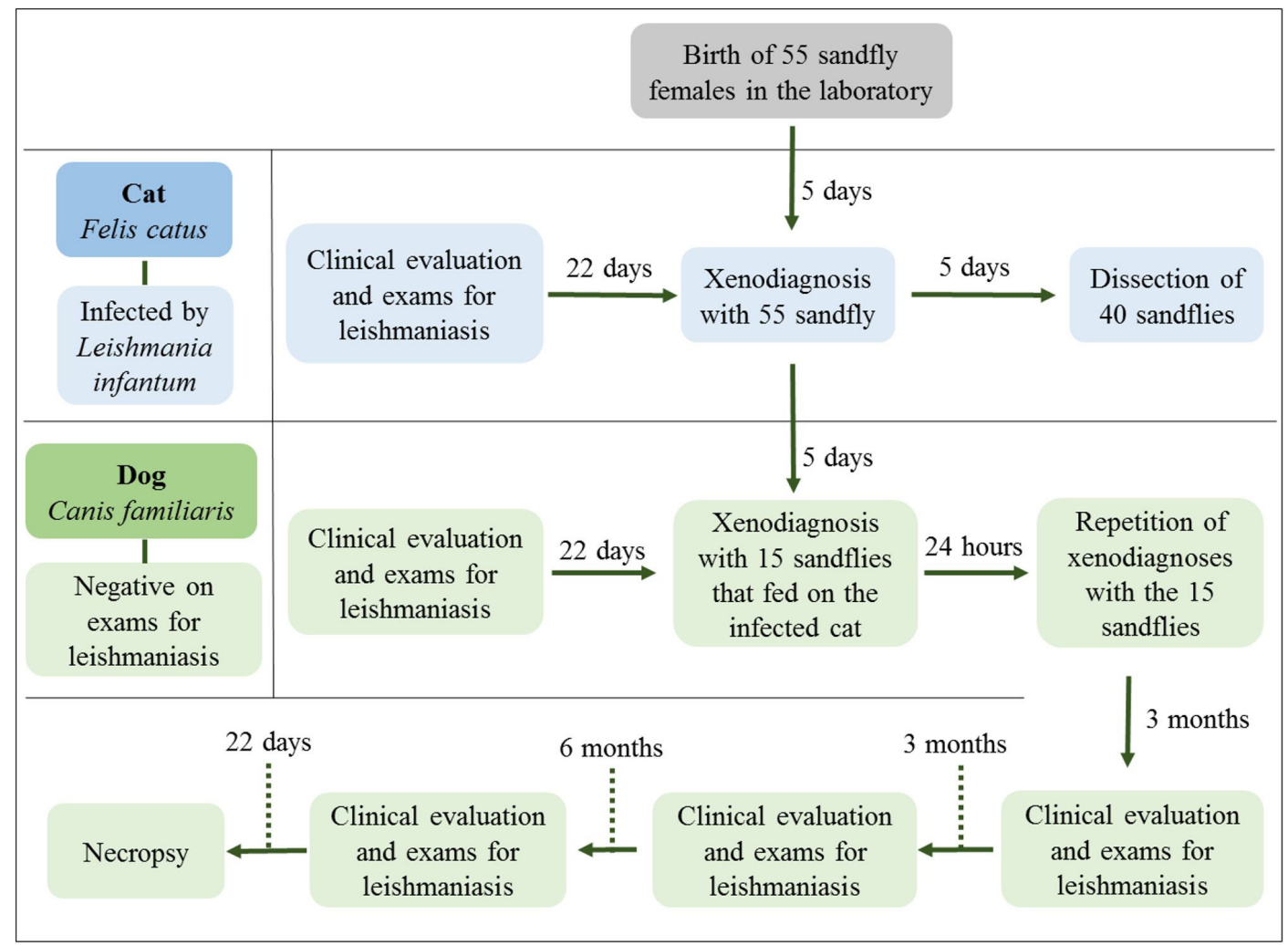

Figure 1. Scheme of the experimental design, showing in the timeline the procedures performed with the sandflies, cat and dog, performed to verify possibility of leishmaniasis transmission from the cat to the dog.
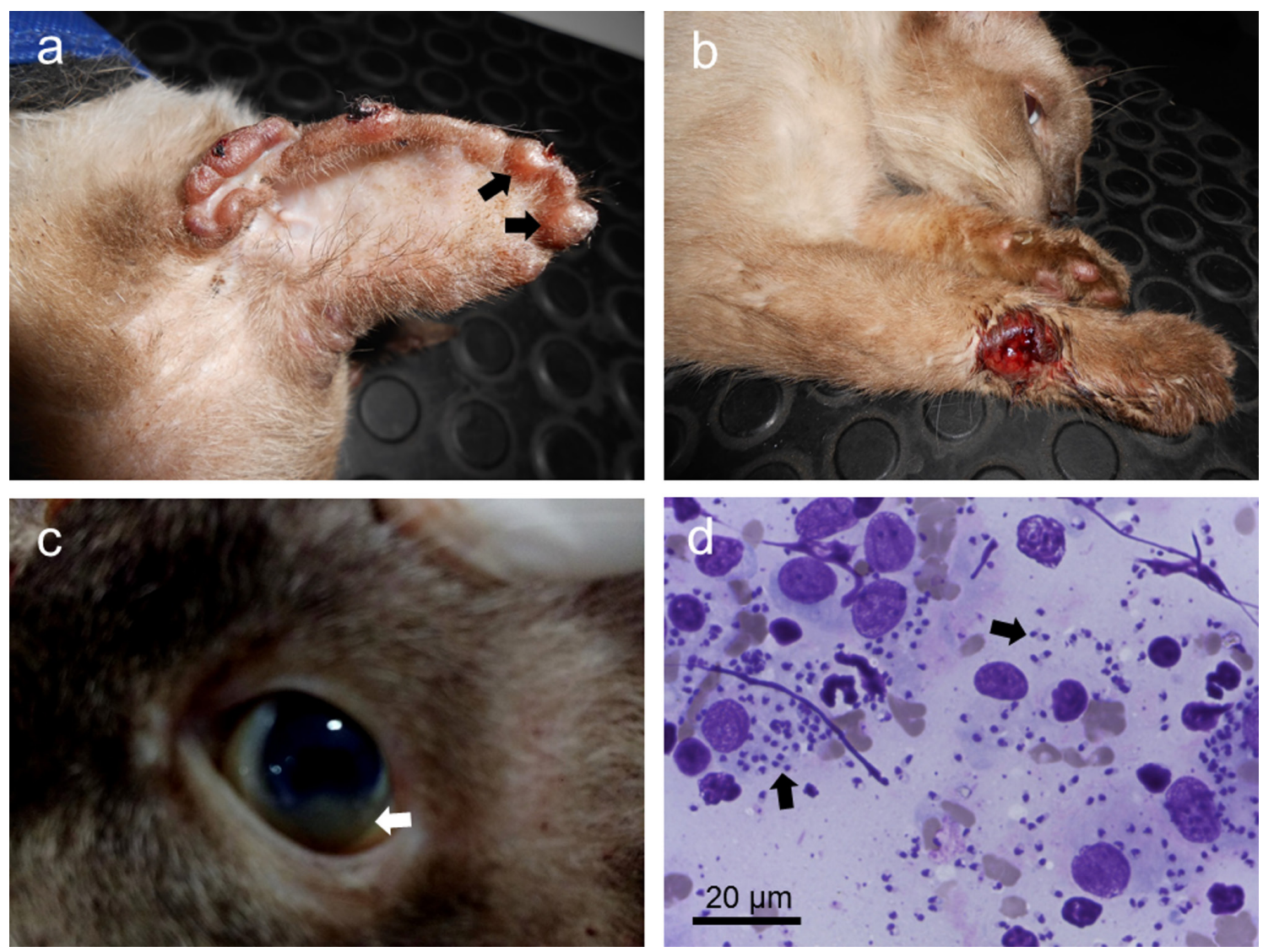

Figure 2. Domestic cat with visceral leishmaniasis. (a) Nodules of softened consistency at the edge of the ear; (b) Lesion on right anterior limb; (c) Uveitis; (d) Leishmania amastigotes in smear of ear nodules scraping stained by Giemsa. 
After parasitological examination for VL, Leishmania was detected in the bone marrow, popliteal lymph node, and skin samples (Figure 2). The animal was also positive by the serological examination enzyme linked immunosorbent assay (ELISA) for anti-Leishmania antibodies, for feline immunodeficiency virus (FIV), Anaplasma sp., and Malassezia sp.

Upon biochemical examination of feline serum, high total protein, increased globulin, low albumin concentration, and low albumin/globulin ratio were observed. On the hemogram, only thrombocytopenia was observed.

\section{Canine characteristics}

The female dog was born at the UFPI animal experimentation kennel, without any clinical alterations suggestive of VL. The mother of the dog used in this study was also found negative by serological tests Rapid Test Dual-path Platform (TR DPP $®)$ and ELISA, direct search for the parasite in bone marrow through the parasitological methods of Leishmania culture and smear stained with Giemsa, and also by the PCR of bone marrow sample.

The dog subjected to the experimental infection was located at a netting protected kennel from birth until the end of the experiment. In the kennel, the box where the dog stayed was fully protected against insects by the netting. There was a protection with a tiny net that allows the airflow, however, making it impossible for any insect to enter the kennel. In addition, fumigations with pest control substances were done to prevent tick emergence and permanency of any other insect. The dog and the environment were monitored daily and no ectoparasite was detected during the experiment.

Six months after birth, the dog was submitted for blood collection for the TR DPP® and ELISA tests and for bone marrow aspiration for parasitological exams (smear stained with Giemsa and Leishmania culture) and PCR, for VL diagnosis. All the tests were negative and did not present any clinical alterations suggestive of VL.

Serological and parasitological examinations of the dog and the puppy were followed by a procedure described by Mendonça et al. (2017b) and PCR as described below.

\section{Polymerase chain reaction (PCR)}

DNA from the bone marrow of the dog was extracted using QIAamp DNA Mini Kit (QIAGEN, Hilden, Germany) as per the manufacturer's instructions.

Ribosomal gene Internal Transcribed Spacer 1 (ITS1) was amplified using primers LITSR (5' -CTG GAT CAT TTT CCG ATG-3') and L5.8S (5'-TGA TAC CAC TTA TCG CAC TT-3') (El Tai et al., 2000). PCR was performed using $12.5 \mu \mathrm{L}$ of "GoTaq ${ }^{\circledR}$ Green Master Mix" (Promega, Madison, Wisconsin, USA), $2.5 \mu \mathrm{L}$ of each primer, and $2.5 \mu \mathrm{L}$ of genomic DNA $3 \mathrm{ng} / \mu \mathrm{L}$, in a final volume of $25 \mu \mathrm{L}$. Veriti ${ }^{\mathrm{TM}}$ Thermal Cycler (Applied Biosystems ${ }^{\circledR}$ ) was used with the following temperature and time conditions: initial denaturation of $95^{\circ} \mathrm{C}$ for $2 \mathrm{~min}, 32$ cycles of $95^{\circ} \mathrm{C}$ for $20 \mathrm{~s}, 53^{\circ} \mathrm{C}$ for $1 \mathrm{~min}$, and $72{ }^{\circ} \mathrm{C}$ for $1 \mathrm{~min}$, and final extension of $72^{\circ} \mathrm{C}$ for $6 \mathrm{~min}$.

The PCR product of 314 bp was analyzed in a vertical electrophoresis system, at $100 \mathrm{~V}$ in $1 \times$ tris-boric acid-EDTA buffer in 5\% acrylamide:bis-acrylamide 39:1 gel stained with silver nitrate.

\section{Vector infection evaluation}

To verify the infectivity of the vector, xenodiagnosis was performed on the $L$. infantum infected feline. Therefore, the animal was sedated using a combination of $15 \mathrm{mg} / \mathrm{kg}$ of ketamine hydrochloride, $0.3 \mathrm{mg} / \mathrm{kg}$ of diazepane $0.03 \mathrm{mg} / \mathrm{kg}$ of acepromazine (0.2\%) and $15 \mathrm{mg} / \mathrm{kg}$ of ride, administered intramuscularly using a $10 \mathrm{~mL}$ syringe with $25 \times 0.8 \mathrm{~mm}$ needle. The L. longipalpis females were obtained from the laboratory sand fly colony at LASAN.

Fifty-five first-generation, 5 days old females deprived of any food source for the $8 \mathrm{~h}$ prior to xenodiagnosis, were placed in dark plastic boxes of approximately $5 \mathrm{~cm}$ length and width and $6 \mathrm{~cm}$ height, with one side open and covered by organza tissue and placed on the cat's outer ear skin for a period of $60 \mathrm{~min}$. This feeding on the cat was the only blood meal for these insects.

Subsequently, those insects were placed in a biochemical oxygen demand (BOD) incubator with a cotton soaked with $50 \%$ sucrose solution. On the $5^{\text {th }}$ day after blood meal, 40 were dissected on a sterile slide for promastigote survey using a 40x objective lens (Mendonça et al., 2017c).

\section{Evaluation of transmission in the dog}

The 15 un-dissected L. longipalpis females were subjected to blood meal sessions on the outside of the dog's ear for $60 \mathrm{~min}$, on the $5^{\text {th }}$ and the $6^{\text {th }}$ day after feeding on the feline. The $5^{\text {th }}$ and $6^{\text {th }}$ day were chosen because $a$ 
large amount of Leishmania was observed in the probocide of L. longipalpis on the $6^{\text {th }}$ day after feeding in a feline infected with L. infantum (Mendonça et al., 2020).

At the $3^{\text {rd }}, 6^{\text {th }}$, and $12^{\text {th }}$ months after the experimental infection, the animal was subjected to clinical evaluation to verify possible development of lesions suggestive of VL. In the same periods, serological tests (TR DPP® and ELISA) and parasitological tests (smear and Leishmania culture) were also carried out to diagnose VL, according to the methodologies described by Mendonça et al. (2017b). During the last evaluation, bone marrow PCR was also performed, according to the methodology as described above.

After evaluating the test results, the animal was subjected to euthanasia, following the guidelines of the CONCEA. $50 \mathrm{mg} / \mathrm{kg}$ sodium thiopental was administered followed by a dose of $1 \mathrm{~mL} / \mathrm{kg}$ potassium chloride (20\%), both intravenously. Subsequently, necropsy was performed to verify possible organ changes, also for spleen and liver aspiration, whose samples were placed in culture medium to grow Leishmania, as described by Mendonça et al. (2017b).

\section{Leishmania identification by sequencing}

Following primer pairs were designed for this study and used to amplify DNA for the complete mini-circle sequencing: Lchag1 144F (5' -TAAACGGGGCTAGGGCTTTG-3'), Lchag1 314R (5'-CATTACCCCGCCACCGAATA-3'), Lchag6 7F (5' -TGTAAAATAGGGCCGGGTGG-3'), Lchag6 202R (5' -CCCACGCATACCCTAAAGCA-3'), Lchag11 $270 \mathrm{~F}$ (5'-GAGGCCGATGGGAATTGGAT-3'), and Lchag11 628R (5' -CCATCCAACACGTCCCAACA-3'), in the following combinations: Lchag1 144F and Lchag1 314R, Lchag6 7F and Lchag6 202R, Lchag11 270F and Lchag11 628R and Lchag11 270F and Lchag6 202R. The primers were designed using the sequences JX156625.1 isolated from L. chagasi and MT598572.1 from L. infantum, published on GenBank. The kDNA mini-circle were used because they have high sensitivity in detecting genetic differences present in Leishmania protozoa (Kocher et al., 2018).

PCR was performed using KOD Plus NEO ${ }^{\circledR}$ Master Mix kit (Toyobo, Japan), by following manufacturer's specifications. The final reaction volume was $50 \mu \mathrm{L}$ and PCR conditions were: $98^{\circ} \mathrm{C}$ for $2 \mathrm{~min}, 30$ cycles of $\left(94^{\circ} \mathrm{C}\right.$ for $30 \mathrm{~s}, 68{ }^{\circ} \mathrm{C}$ for $30 \mathrm{~s}$ ) and $72{ }^{\circ} \mathrm{C}$ for $7 \mathrm{~min}$. Amplified fragments were purified using the Fast Gene Gel/PCR extraction kit (Nippon Genetics, Koraku Korakumori, Bunkyo-ku, Japan) for amplified DNA purification, according to manufacturer's instructions. The purified product was sequenced in an ABI3730XL sequencer machine (Applied Biosystems, Foster City, California, USA) at the Department of Tropical Medicine and Parasitology at Dokkyo Medical University, as described by Sanguankiat et al. (2016) and Sato et al. (2017).

Automatically generated base sequences were analyzed using the ChromasPro program version 2.1.6 and submitted to similarity search with the nucleotide sequences available in GenBank using the BLASTn tool (NCBI, 2020).

\section{Results}

\section{Evaluation of the vector infection}

Through the xenodiagnosis of the feline, it was observed that all $55 \mathrm{~L}$. longipalpis females were fed and were visibly engorged.

Of the 40 dissected females, 11 (27.5\%) became infected during the blood feeding on the feline. In all infected insects, Leishmania promastigotes were detected in the metacyclic form in their stomachs (Figure 3). In 1 out of 11, besides the presence of the parasite in the stomach, metacyclic promastigotes were also found in its anterior intestine.

\section{Evaluation of L. infantum transmission into the dog}

During the dog's evaluation after 3 months of the experimental infection, an increase in popliteal lymph nodes was observed, serological tests (TR DPP $®$ and ELISA) were reactive, and Leishmania culture using popliteal lymph node sample was positive. However, Leishmania sp. was not detected in bone marrow during the first post-infection evaluation.

Six months post-infection, besides enlarged popliteal lymph nodes, alopecia was also observed, with major intensity in periocular and abdominal regions (Figure 4a). Serological tests (TR DPP $®$ and ELISA) remained positive also in popliteal lymph node culture, but still negative in direct search of the parasite in bone marrow. 


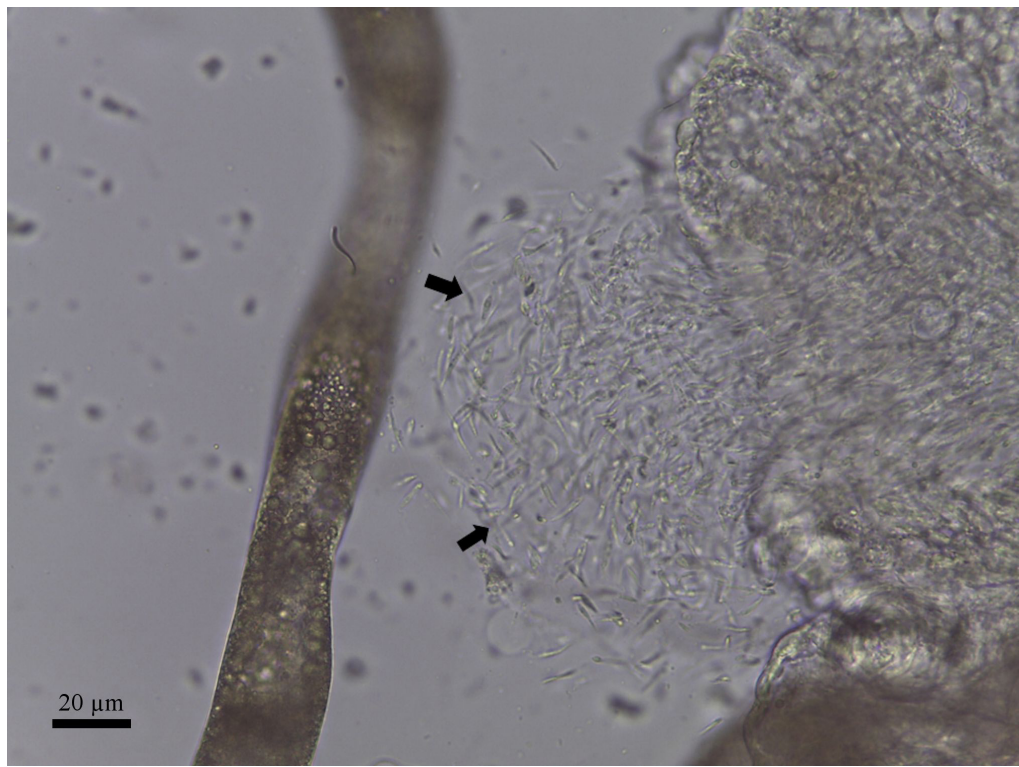

Figure 3. Leishmanias in promastigote form coming out of the vector L. longipalpis stomach, which had fed on the cat infected by L. infantum.
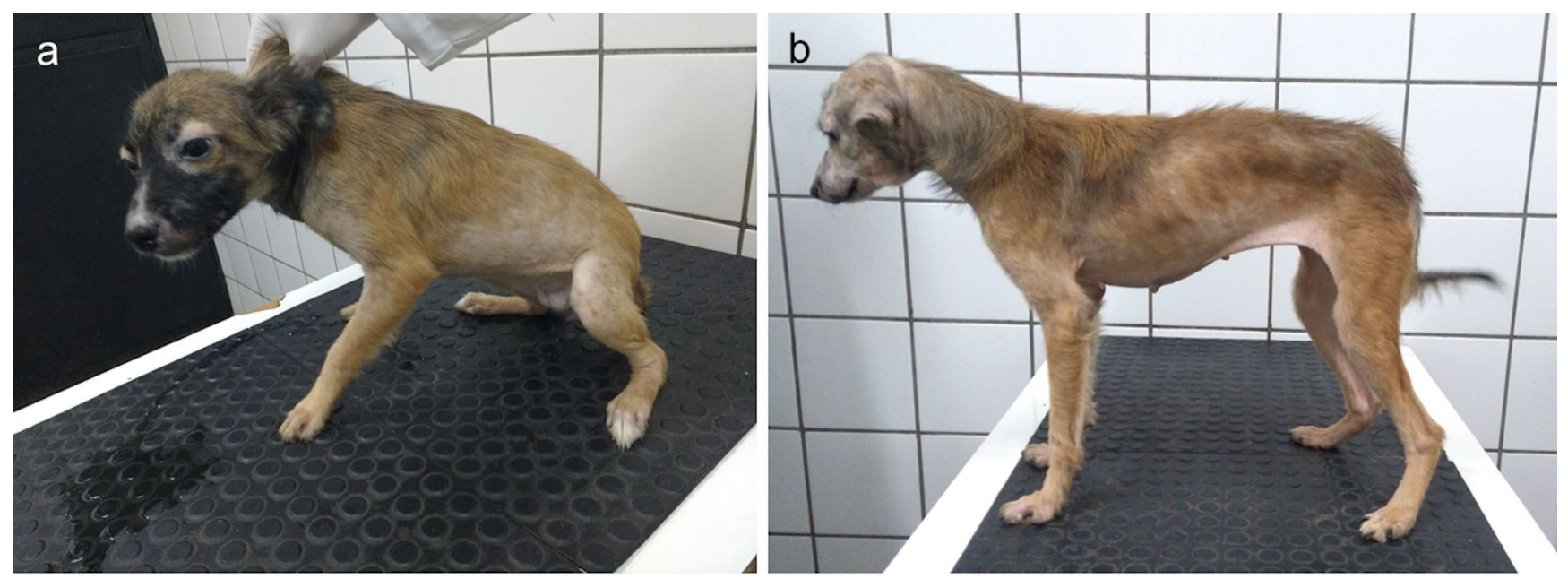

Figure 4. Clinical characteristics of the dog subjected to experimental infection by L. infantum, through the insect vector infected by the feline with VL. (a) 3 months post-infection; (b) 12 months post-infection.

Twelve months after experimental infection, the dog was again evaluated. In this last evaluation, the dog had enlarged lymph nodes, lesions on the face and ear, generalized alopecia, and weight loss (Figure 4b). Serological tests (TR DPP® and ELISA) and Leishmania culture using popliteal lymph node sample were positive. However, PCR and Leishmania culture using bone marrow sample were negative and the parasite was not detected in skin smear. In necropsy, only splenomegaly was detected, however, Leishmania cultures of spleen and liver aspirates were negative.

\section{Leishmania identification by sequencing}

All nucleotide sequences obtained through the complete Leishmania kinetoplast microcircle sequencing isolated from bone marrow, popliteal lymph nodes, and feline ear nodules, showed $100 \%$ similarity to its sequences and $99 \%$ with the L. chagasi sequences JX156617.1 and JX156624.1 isolated from dogs and 98\% with the L. infantum sequence AJ275334.1 isolated from human registered in GenBank (Figure 5) and (Supplementary file, Figure S1). In addition, when performing a search for nucleotide sequences compatible with feline Leishmania sequence through BLASTn, all of the sequences in the list were compatible with the Leishmania responsible for causing VL in dogs or humans. 
Leishmania(1) Leishmania(2) Leishmania(3) AJ275334.1 JX156617.1 JX156624.1

Leishmania(1) Leishmania(2) Leishmania(3) AJ 275334.1 JX156617.1

JX156624.1

Leishmania(1) Leishmania(2) Leishmania(3)

AJ275334.1

JX156617.1 JX156624.1

Leishmania(1) Leishmania(2) Leishmania( 3 ) A] 275334.1 JX156617.1 JX156624.1

Leishmania(1) Leishmania(2) Leishmania (3) AJ275334.1 JX156617.1 JX156624.1

Leishmania (1) Leishmania(2) Leishmania(3) A 275334.1 JX156617.1 JX156624.1

Leishmania(1) Leishmania(2) Leishmania( 3 ) AJ 275334.1 JX156617.1 JX156624.1

Leishmania(1) Leishmania(2) Leishmania( 3 ) AJ 275334.1

JX156617.1

JX156624.1

Leishmania (1) Leishmania(2) Leishmania(3)

A]275334.1

JX156617.1

JX156624.1

Leishmania (1) Leishmania(2) Leishmania( 3 ) AJ275334.1 JX156617.1 $\mathrm{J} \times 156624.1$
GGGTAAGCGTGACATATAGTCAAGTTATATTGTGAGTITACGAATCAATT GGGTAAGCGTGACATATAGTCAAGTTATATTGTGAGTITACGAATCAATT GGGTAAGCGTGACATATAGTCAAGTTATATTGTGAGTITACGAATCAATT GGGTAAGCGTGACATATAGTCAAGTTATATTGTGAGTTTACGAATCAATT GGGTAAGCGTGACATATAGTCAAGTTATATTGTGAGTTTACGAATCAATT GGGTAAGCGTGACATATAGTCAAGTTATATTGTGAGTITACGAATCAATT

GGACTIAGCGCCTACTCATACATTATATACTCTIGAATGTGAAGTTITTG GGACTTAGCGCCTACTCATACATTATATACTCTTGAATGTGAAGTTTITG GGACTTAGCGCCTACTCATACATTATATACTCTTGAATGTGAAGTITITG GGACTTAGCGCCTACTCATACATTATATACTCTTGAATGTGAAGTIIITG GGACTTAGCGCCTACTCATACATTATATACTCTTGAATGTGAAGTIIITG GGACTTAGCGCCTACTCATACATTATATACTCTTGAATGTGAAGTTITTG

ATCTGTTTGGTTATGTTATGATCGAGGCTGACACAATTTGATGGCCTGTG ATCTGTITGGTTATGTTATGATCGAGGCTGACACAATTTGATGGCCTGTG ATCTGTITGGTTATGTTATGATCGAGGCTGACACAATTTGATGGCCTGTG ATCTGTITGGTTGTGTTATGATCGAGGCTGACACAATTTGATGGCCTGTG ATCTGTITGGTTATGTTATGATCGAGGCTGACACAATTTGATGGCCTGTG ATCTGTITGGTTATGTTATGATCGAGGCTGACACAATTTGATGGCCTGTG

TAAATATATCTTACCTTAAGGTGGCTTCTITGAAATGCAATTTGAATTAA TAAATATATCTTACCTTAAGGTGGCTTCTITGAAATGCAATTITGAATTAA TAAATATATCTTACCTTAAGGTGGCTTCTTTGAAATGCAATTTGAATTAA TAAATATATCTTACCTTAAGGTGGCTTCTITGAAATGCAATITGAATTAA TAAATATATCTTACCTTAAGGTGGCTTCTITGAAATGCAATTTGAATTAA TAAATATATCTIACCTTAAGGTGGCTTCTITGAAATGCAATITGAATTAA TITGGGGATGGGTTGC-TGGAGGTGTTGGGACGTGTTGGATGGTTGGGAA TITGGGGATGGGTTGC - TGGAGGTGTTGGGACGTGTTGGATGGTTGGGAA TITGGGGATGGGTTGC-TGGAGGTGTTGGGACGTGTTGGATGGTTGGGAA TITGGGGATGGATTGCCTGGAGGTGTTGGGACGTGTTGGATGGTTGGGGA TITGGGGATGGGTTGC-TGGAGGTGTTGGGACGTGTTGGATGGTTGGGAA TTTGGGGATGGGTTGC - TGGAGGTGTTGGGGCGTGTTGGATGGTTGGGAA

TTGGTGGGAAATCCCGAAAAATGGTCGAAAAATGCCAAAAATCCCAAACT TTGGTGGGAAATCCCGAAAAATGGTCGAAAAATGCCAAAAATCCCAAACT TTGGTGGGAAATCCCGAAAAATGGTCGAAAAATGCCAAAAATCCCAAACT TTGGTGGAAAATCCCGAAAAATGGTCGAAAAATGCCAAAAATCCCAAACT TTGGTGGAAAATCCCGAAAAATGGTCGAAAAATGCCAAAAATCCCAAACT TTGGTGGGAAATCCCGAAAAATGGTCGAAAAATGCCAAAAATCCCAAACT TITCTGGTCCTCCGGGTAGGGGCGTICTGCAAAATCGGAAAAATGGGTGC TITCTGGTCCTCCGGGTAGGGGCGTTCTGCAAAATCGGAAAAATGGGTGC TITCTGGTCCTCCGGGTAGGGGCGTTCTGCAAAATCGGAAAAATGGGTGC TITCTGGTCCTTCGGGTAGGGGCGTTCTGCGAAAATCGAAAAATGGGTGC TTTCTGGTCCTCCGGGTAGGGGCGTTC TITCTGGTCCTCCGGG

AGAAATCCCGTTCAAAAAATGGCCCAAAATGCCAAAAATGGGCTCCGGGG AGAAATCCCGTTCAAAAAATGGCCCAAAATGCCAAAAATGGGCTCCGGGG AGAAATCCCGTTCAAAAAATGGCCCAAAATGCCAAAAATGGGCTCCGGGG AGAAATCCCGTTCAAAAAATGGCCCAAAATGCCAAAAATGGGCTCCGGGG

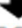

CGGGAAACTGGGGGTTGGTGTAAAATAGGGCCGGGTGGTGGTCGGGAATG CGGGAAACTGGGGGTTGGTGTAAAATAGGGCCGGGTGGTGGTCGGGAATG CGGGAAACTGGGGGTTGGTGTAAAATAGGGCCGGGTGGTGGTCGGGAATG CCGGAAACTGG -

GGCTACCCTGGGCTGGATTGGCCTGGACCCCTGGGTCTGGAGGCTTGATI GGCTACCCTGGGCTGGATTGGCCTGGACCCCTGGGTCTGGAGGCTTGATT GGCTACCCTGGGCTGGATTGGCCTGGACCCCTGGGTCTGGAGGCTTGATT
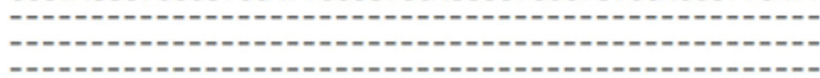

Figure 5. Multiple nucleotide sequence alignments from isolated cat leishmanias (Leishmania(1) from bone marrow, Leishmania(2) from popliteal lymph node and Leishmania(3) from ear nodule) and sequences from Leishmania infantum AJ275334. 1 isolated from human and Leishmania chagasi JX156617.1 and JX156624.1 isolated from dogs registered on GenBank.

\section{Discussion}

VL control in Brazil is based on the use of insecticides and mainly on the detection and euthanasia of infected dogs (Brasil, 2014). However, in a systematic review of these disease control strategies in Latin America, it was noticed that there was no significant reduction in the number of cases by eliminating VL-positive dogs (Romero \& Boelaert, 2010). Other studies also suggest that the dog sacrifice as the primary measure of VL control is not effective in reducing the incidence of human or canine cases in urban areas over time (Dietze et al., 1997; Ashford et al., 
1998; Costa, 2008; Nunes et al., 2008; Oliveira et al., 2008). Therefore, indicating the possibility of other reservoirs of this parasite in the urban environment.

Besides dogs and other possible reservoirs (rodents, opossums, and foxes), infections in domestic cats have been demonstrated (Benassi et al., 2017; Akhtardanesh et al., 2017; Otranto et al., 2017). These animals need special attention due to its proximity to humans and the increase of their population in recent years (Dabritz \& Conrad, 2010). In addition, the results of this study demonstrate that felines appear to be an excellent source of food for sand flies, since all insects used in this study were visibly engorged after xenodiagnostic procedure in the feline.

Also, noteworthy were the presence of Leishmania in the cat's ear skin, the high frequency of infected insects (27.5\%), and the high promastigotes number already in the metacyclic form inside the insect's stomach. In a study with dogs, it was demonstrated that the frequency of infected insects when fed on infected dogs was lower than that observed in insects fed on infected felines, even in dogs that showed clinical signs of the disease (Borja et al., 2016; Mendonça et al., 2017c). These findings are indicative of significant feline participation in biological cycle of L. infantum.

Regarding the effective participation of the cat in the epidemiological cycle of $L$. infantum, further studies will be necessary to clarify how much sandflies are attracted to feed on felines in the natural environment, despite the strong evidence of high attractiveness in experimental conditions, in which it was observed in this study that all females of $L$. longipalpis were visibly engorged. Many cats have also been reported to be infected with $L$. infantum (Savani et al., 2004; Vides et al., 2011; Coelho et al., 2011; Benassi et al., 2017; Metzdorf et al., 2017; Mendonça et al., 2017a), suggesting that felines are used as a food source by sandflies, due to the fact that vector transmission is considered the main form of infection in cats (Pennisi \& Persichetti, 2018).

In addition to aforementioned findings, the main finding of this study was the confirmation of infection transmission from the infected feline to the dog through the biological vector (L. longipalpis). With these findings, not only the possibility of vector infection is evident, but also the transmission to another host (dog) and possibly to other species including humans. When evaluating the nucleotide sequence produced by Leishmania sequencing isolated from the feline in this study, 99\% similarity was observed with the sequences JX156624.1 and JX156617.1 of L. chagasi from dogs and $98 \%$ with the sequence AJ275334.1 of L. infantum from human infection. This similarity of parasites' genetic characteristics is a further evidence of infection transmission possibility to humans.

The inability of parasite detection in bone marrow, skin, spleen, and liver can be answered by a possible efficient immune response developed by the dog, which may have prevented rapid multiplication of parasite and its dissemination to these organs. It is also necessary to consider the possibility that a small amount of parasites have been transmitted to the dog, delaying the spread in sufficient quantities to be detected in the methods used. In a study developed by Gossage et al. (2003), it was observed that L. infantum's metacyclic promastigote (infective form) reaches a high prevalence in the sand fly on the $10^{\text {th }}$ day after infection. Despite the presence of promastigotes in the probocide of L. longipalpis on the $6^{\text {th }}$ day after infection (Mendonça et al., 2020), possibly in this study, a small amount of metacyclic promastigotes has infected the dog, favoring the control of the infection by the immune response.

In fact, the need for new studies is necessary to better understand the behavior of L. infantum in dogs, which present different profiles of immune response when infected with parasite from felines. In addition, new studies are also required to verify the infection prevalence in felines at local and national level, in order to analyze the genetic characteristics of feline L. infantum, as well as to prove the transmission of feline infection to other hosts in the natural environment.

To conclude, with this study, it was possible to demonstrate that L. longipalpis feed on felines, become infected with $L$. infantum while feeding on infected domestic cat, and transmit $L$. infantum from the feline to the dog. Thus, the possible participation of a domestic cat in the VL epidemiology in Teresina, state of Piauí, it was reinforced through this study being the first to report the experimental transmission of $L$. infantum from felines to another host, through the sand fly as a vector.

\section{Acknowledgements}

We would like to thank Editage (www.editage.com) for English language editing.

\section{References}

Akhtardanesh B, Sharifi I, Mohammadi A, Mostafavi M, Hakimmipour M, Pourafshar NG. Feline visceral leishmaniasis in Kerman, southeast of Iran: serological and molecular study. J Vector Borne Dis 2017; 54(1): 96-102. PMid:28352052. 
Asfaram S, Fakhar M, Teshnizi SH. Is the cat an important reservoir host for visceral leishmaniasis? A systematic review with meta-analysis. J Venom Anim Toxins Incl Trop Dis 2019; 25: e20190012. http://dx.doi.org/10.1590/1678-9199-jvatitd-2019-0012. PMid:31258555.

Ashford DA, David JR, Freire M, David R, Sherlock I, Eulálio MC, et al. Studies on control of visceral leishmaniasis: impact of dog control on canine and human visceral leishmaniasis in Jacobina, Bahia, Brazil. Am J Trop Med Hyg 1998; 59(1): 53-57. http://dx.doi. org/10.4269/ajtmh.1998.59.53. PMid:9684628.

Benassi JC, Benvenga GU, Ferreira HL, Pereira VF, Keid LB, Soares R, et al. Detection of Leishmania infantum DNA in conjunctival swabs of cats by quantitative real-time PCR. Exp Parasitol 2017; 177: 93-97. http://dx.doi.org/10.1016/j.exppara.2017.04.004. PMid:28438522.

Borja LS, Sousa OMF, Solcà MDS, Bastos LA, Bordoni M, Magalhães JT, et al. Parasite load in the blood and skin of dogs naturally infected by Leishmania infantum is correlated with their capacity to infect sand fly vectors. Vet Parasito/ 2016; 229: 110-117. http:// dx.doi.org/10.1016/j.vetpar.2016.10.004. PMid:27809965.

Brasil. Ministério da Saúde. Manual de vigilância e controle da leishmaniose visceral. 1. ed. Brasília: Ministério da Saúde; 2014.

Coelho WM, Richini-Pereira VB, Langoni H, Bresciani KD. Molecular detection of Leishmania sp. in cats (Felis catus) from Andradina Municipality, São Paulo State, Brazil. Vet Parasitol 2011; 176(2-3): 281-282. http://dx.doi.org/10.1016/j.vetpar.2010.10.052. PMid:21130575.

Costa $\mathrm{CH}$. Characterization and speculations on the urbanization of visceral leishmaniasis in Brazil. Cad Saude Publica 2008; 24(12): 2959-2963. http://dx.doi.org/10.1590/S0102-311X2008001200027. PMid:19082289.

Dabritz HA, Conrad PA. Cats and Toxoplasma: implications for public health. Zoonoses Public Health 2010; 57(1): 34-52. http:// dx.doi.org/10.1111/j.1863-2378.2009.01273.x. PMid:19744306.

Dietze R, Barros GB, Teixeira L, Harris J, Michelson K, Falqueto A, et al. Effect of eliminating seropositive canines on the transmission of visceral leishmaniasis in Brazil. Clin Infect Dis 1997; 25(5): 1240-1242. http://dx.doi.org/10.1086/516096. PMid:9402389.

El Tai NO, Osman OF, El Fari M, Presber W, Schönian G. Genetic heterogeneity of ribosomal internal transcribed spacer in clinical samples of Leishmania donovani spotted on filter paper as revealed by single-strand conformation polymorphisms and sequencing. Trans R Soc Trop Med Hyg 2000; 94(5): 575-579. http://dx.doi.org/10.1016/S0035-9203(00)90093-2. PMid:11132393.

Gossage SM, Rogers ME, Bates PA. Two separate growth phases during the development of Leishmania in sand flies: implications for understanding the life cycle. Int J Parasitol 2003; 33(10): 1027-1034. http://dx.doi.org/10.1016/S0020-7519(03)00142-5. PMid:13129524.

Harhay MO, Olliaro PL, Costa DL, Costa CHN. Urban parasitology: visceral leishmaniasis in Brazil. Trends Parasitol 2011; 27(9): 403-409. http://dx.doi.org/10.1016/j.pt.2011.04.001. PMid:21596622.

Kocher A, Valière S, Bañuls AL, Murienne J. High-throughput sequencing of kDNA amplicons for the analysis of Leishmania minicircles and identification of Neotropical species. Parasitology 2018; 145(5): 585-594. http://dx.doi.org/10.1017/S0031182017002013. PMid:29144208.

Marcondes M, Rossi CN. Leishmaniose visceral no Brasil. Braz J Vet Res Anim Sci 2013; 50(5): 341-352. http://dx.doi.org/10.11606/ issn.2318-3659.v50i5p341-352.

Maroli M, Pennisi MG, Di Muccio T, Khoury C, Gradoni L, Gramiccia M. Infection of sandflies by a cat naturally infected with Leishmania infantum. Vet Parasitol 2007; 145(3-4): 357-360. http://dx.doi.org/10.1016/j.vetpar.2006.11.009. PMid:17174035.

Mello GB. Verificação da infecção natural do gato (Felix domesticus) por um protozoario do genero Leishmania. Bras Med 1940; 54: 180.

Mendonça IL, Batista JF, Lopes KSPP, Magalhães No FCR, Alcântara DS, Merigueti YFFB, et al. Infection of Lutzomyia longipalpis in cats infected with Leishmania infantum. Vet Parasitol 2020; 280: 109058. http://dx.doi.org/10.1016/j.vetpar.2020.109058. PMid:32200198.

Mendonça IL, Batista JF, Ribeiro IMM, Rocha FSB, Silva SO, Melo MN. Leishmania infantum in domestic cats from the municipality of Teresina, state of Piauí, Brazil. Parasitol Open 2017a; 3: e1. http://dx.doi.org/10.1017/pao.2017.1.

Mendonça IL, Batista JF, Schallig H, Cruz MSP, Alonso DP, Ribolla PEM, et al. The performance of serological tests for Leishmania infantum infection screening in dogs depends on the prevalence of the disease. Rev Inst Med Trop São Paulo 2017b; 59(0): e39. http://dx.doi.org/10.1590/s1678-9946201759039. PMid:28591267.

Mendonça IL, Batista JF, Werneck GL, Soares MRA, Costa DL, Costa CHN. Serological tests fail to discriminate dogs with visceral leishmaniasis that transmit Leishmania infantum to the vector Lutzomyia longipalpis. Rev Soc Bras Med Trop 2017c; 50(4): 483-488. http://dx.doi.org/10.1590/0037-8682-0014-2017. PMid:28954069. 
Metzdorf IP, Lima MSC Jr, Matos MFC, Souza AF Fo, Tsujisaki RAS, Franco KG, et al. Molecular characterization of Leishmania infantum in domestic cats in a region of Brazil endemic for human and canine visceral leishmaniasis. Acta Trop 2017; 166: 121125. http://dx.doi.org/10.1016/j.actatropica.2016.11.013. PMid:27851895.

National Center for Biotechnology Information - NCBI. Basic Local Alignment Search Tool (BLAST) [online]. Bethesda; 2020 [cited 2020 Aug 12]. Available from: https://blast.ncbi.nlm.nih.gov/Blast.cgi

Nunes CM, Lima VMF, Paula HB, Perri SHV, Andrade AM, Dias FEF, et al. Dog culling and replacement in an area endemic for visceral leishmaniasis in Brazil. Vet Parasito/ 2008; 153(1-2): 19-23. http://dx.doi.org/10.1016/j.vetpar.2008.01.005. PMid:18314275.

Oliveira CDL, Morais MHF, Machado-Coelho GLL. Visceral leishmaniasis in large Brazilian cities: challenges for control. Cad Saude Publica 2008; 24(12): 2953-2958. http://dx.doi.org/10.1590/S0102-311X2008001200026. PMid:19082288.

Otranto D, Napoli E, Latrofa MS, Annoscia G, Tarallo VD, Greco G, et al. Feline and canine leishmaniosis and other vector-borne diseases in the Aeolian Islands: pathogen and vector circulation in a confined environment. Vet Parasitol 2017; 236: 144-151. http://dx.doi.org/10.1016/j.vetpar.2017.01.019. PMid:28288759.

Pennisi MG, Persichetti MF. Feline leishmaniosis: is the cat a small dog? Vet Parasito/2018; 251: 131-137. http://dx.doi.org/10.1016/j. vetpar.2018.01.012. PMid:29426470.

Romero GAS, Boelaert M. Control of visceral leishmaniasis in Latin America: a systematic review. PLoS Neg/ Trop Dis 2010; 4(1): e584. http://dx.doi.org/10.1371/journal.pntd.0000584. PMid:20098726.

Sanguankiat S, Sato MO, Sato M, Maipanich W, Yoonuan T, Pongvongsa T, et al. First record of paramphistomes Fischoederius cobboldi and Paramphistomum epiclitum detected in bovine rumen from a local market of savannakhet province, Lao PDR. Korean J Parasitol 2016; 54(4): 543-547. http://dx.doi.org/10.3347/kjp.2016.54.4.543. PMid:27658609.

Sato MO, Sato M, Yoonuan T, Pongvongsa T, Sanguankiat S, Kounnavong S, et al. The role of domestic dogs in the transmission of zoonotic helminthes in a rural area of Mekong river basin. Acta Parasitol 2017; 62(2): 393-400. http://dx.doi.org/10.1515/ap2017-0047. PMid:28426425.

Savani ESMM, Camargo MCO, Carvalho MR, Zampieri RA, Santos MG, D'Auria SR, et al. The first record in the Americas of an autochthonous case of Leishmania (Leishmania) infantum chagasi in a domestic cat (Felix catus) from Cotia County, São Paulo State, Brazil. Vet Parasitol 2004; 120(3): 229-233. http://dx.doi.org/10.1016/j.vetpar.2004.01.008. PMid:15041097.

Silva SM, Rabelo PF, Gontijo NF, Ribeiro RR, Melo MN, Ribeiro VM, et al. First report of infection of Lutzomyia longipalpis by Leishmania (Leishmania) infantum from a naturally infected cat of Brazil. Vet Parasitol 2010; 174(1-2): 150-154. http://dx.doi. org/10.1016/j.vetpar.2010.08.005. PMid:20832944.

Souza GD, Santos E, Andrade JD Fo. The first report of the main vector of visceral leishmaniasis in America, Lutzomyia longipalpis (Lutz \& Neiva) (Diptera: Psychodidae: Phlebotominae), in the state of Rio Grande do Sul, Brazil. Mem Inst Oswaldo Cruz 2009; 104(8): 1181-1182. http://dx.doi.org/10.1590/S0074-02762009000800017. PMid:20140381.

Vides JP, Schwardt TF, Vicente So LS, Marinho M, Laurenti MD, Biondo AW, et al. Leishmania chagasi infection in cats with dermatologic lesions from an endemic area of visceral leishmaniosis in Brazil. Vet Parasitol 2011; 178(1-2): 22-28. http://dx.doi. org/10.1016/j.vetpar.2010.12.042. PMid:21282011.

Zanette MF, Lima VMF, Laurenti MD, Rossi CN, Vides JP, Vieira RFC, et al. Serological cross-reactivity of Trypanosoma cruzi, Ehrlichia canis, Toxoplasma gondii, Neospora caninum and Babesia canis to Leishmania infantum chagasi tests in dogs. Rev Soc Bras Med Trop 2014; 47(1): 105-107. http://dx.doi.org/10.1590/0037-8682-1723-2013. PMid:24603745. 
Transmission of Leishmania: cats to dogs

\section{Supplementary Material}

Supplementary material accompanies this paper.

Figure S1. Alignment of the nucleotide sequence of Leishmania infantum isolated from the cat with the sequences from Leishmania infantum AJ275334.1 isolated from human and Leishmania chagasi JX156617.1 and JX156624.1 isolated from dogs registered on GenBank.

This material is available as part of the online article from http://www.scielo.br/RBPV 